\title{
26
}

\section{Stormwater Management Model for Environmental Design of Permeable Pavement}

\author{
W. Robert C. James, William James and Harald von Langsdorff
}

Permeable pavement is a key component in reproducing pre-development hydrologic regimes, because it can reduce surface runoff, improve water quality and recharge groundwater. In designing a permeable pavement installation, it is fundamentally important to provide and maintain surface infiltration capacity that allows an adequate volume of stormwater to be captured and treated by the facility. This chapter details the underlying method and function of a free-ware program that uses the US EPA Stormwater Management Model (SWMM) for the design of permeable pavement installations.

\subsection{Introduction: Permeable Pavement}

Permeable pavement is a structural stormwater best management practice (BMP) that is capable of reducing surface runoff, improving stormwater quality and recharging groundwater (Thompson and James, 1995). Infiltration capacity of the permeable pavement depends on factors such as surface infiltration, slope, and sub-surface ponding (Kresin et al., 1996).

Impairment of receiving waters is reduced by infiltration. For instance, thermal enrichment of stormwater is one of most important effects of urbanization in cold-water fishery areas - it destroys fish and aquatic ecosystems, and affects other indicators like oxygen concentration or pollutant concentration, because of the temperature dependence of many related processes (James and Verspagen, 1996). Many species of fish are extremely

James, R., W. James and H. von Langsdorff. 2001. "Stormwater Management Model for Environmental Design of Permeable Pavement." Journal of Water Management Modeling R207-26. doi: 10.14796/JWMM.R207-26.

(c) CHI 2001 www.chijournal.org ISSN: 2292-6062 (Formerly in Models and applications to Urban Water Systems. ISBN: 0-9683681-4-X) 
sensitive to temperature changes during their life cycle, and the impact of increased temperatures on rivers and streams is magnified during storm events - it reduces dissolved oxygen saturation levels, increases respiration rates, and disrupts the food chain. The relationship between thermal enrichment and percent imperviousness is well known (James and Xie, 1999). Moreover, previous workers established that urban surfaces in watersheds have the greatest influence on the stream temperature of headwater streams (Xie and James, 1994).

Another important pollutant that is removed or reduced by permeable pavement is related to turbidity, viz. the concentration of settleable or suspended solids (James and Thompson, 1996; James and Shaheen, 1997).

Provision of sufficient surface infiltration capacity to allow an adequate volume of stormwater runoff to be captured and treated by the facility is key (Kipkie and James, 1999). It is not difficult to design and construct a system with appropriate infiltration capacities, but maintaining infiltration capacity over several years is a challenge. Infiltration basins, infiltration trenches, and porous pavements all change in their response to rainfall as time progresses, due to clogging and maintenance practices.

Several different types of permeable pavement are available, and an example that provides drainage cells external to the shape of the paver stone, such that structural forces are not transmitted through the drainage cell, is shown in Figure 26.1. A typical application is shown in Figure 26.2. Further details are provided by Rollings and Rollings (1993).

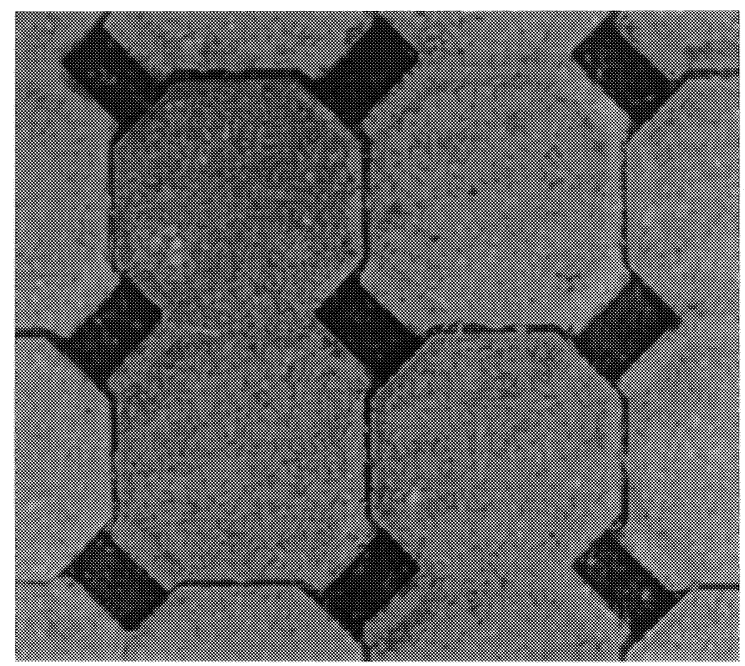

Figure 26.1 UNI Eco-Stone permeable pavers. 


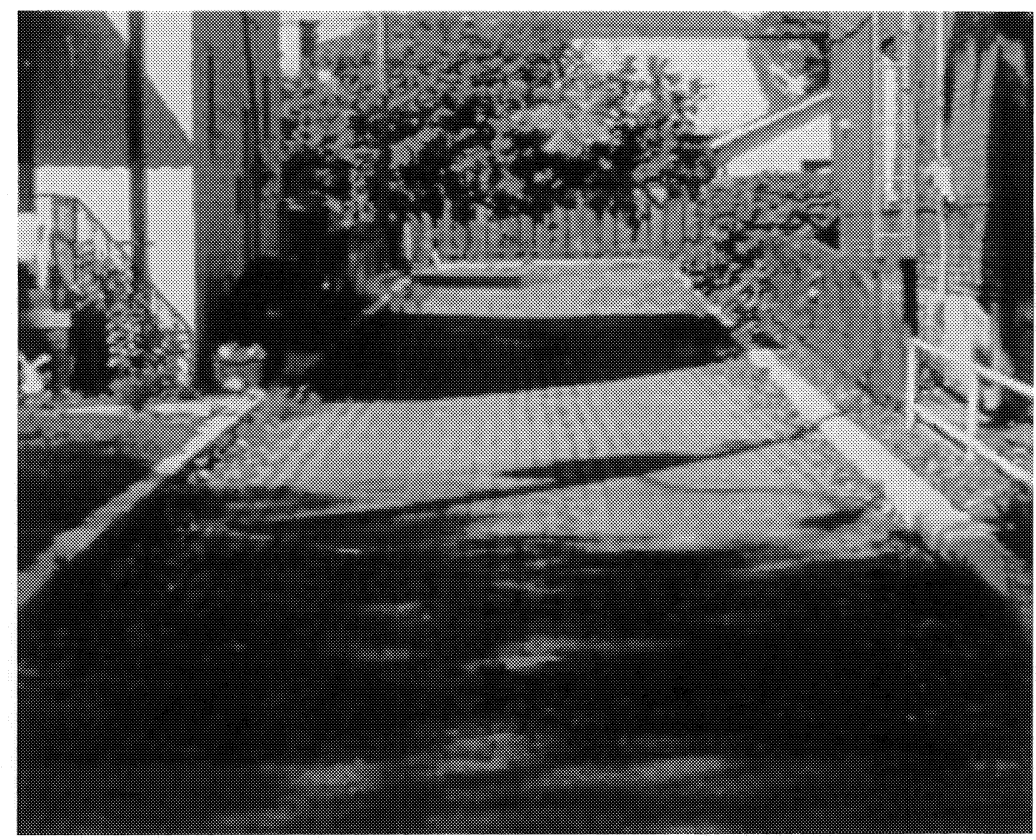

Figure 26.2 Typical application of permeable pavers.

Due to the response of small urban areas to small rainfall events, special hydrological design conditions must be met. Firstly, because of the relatively small areas involved, short computational time steps (e.g. 1 minute) are required, as are short duration design events (e.g. 1 h). Secondly, the reservoir in the pavement sub-base must be properly sized, based on its drainage outlet capacity and the porosity of the constituent crushed rock.

\subsection{PCSWMM for Permeable Pavement}

PCSWMM for Permeable Pavements (PCSWMMPP) was developed specifically for the hydrologic design of permeable pavements. It allows the user to develop a model of a permeable pavement installation, run the model with a selected design storm, and analyze the results of the model to determine whether the design was successful. A successful design is assumed to be one in which the entire volume of the design storm is captured by the permeable pavement installation (i.e. no surface runoff occurs). PCSWMMPP only focuses on the hydrologic and hydraulic aspects of permeable pavement design. No structural requirements are addressed or analyzed. 
User input is via the Input Wizard, an interface that steps the user through the required parameters of the model (James and James, 1995). The model analysis engine is the Runoff module of SWMM4.30. PCSWMMPP's output includes an indication of design success, a summary report and graphs. The summary echoes the user-defined input and tabulates numerical results. The graphs include the input function (design storm), surface runoff (if any), depth of water in the base material, and drainage flow from the base material, for the duration of the model run.

Probably the two main concerns that PCSWMMPP addresses are:

1. what is the maximum depth of water that will occur in a design with design storm $\mathrm{X}$ ?, and

2. how long will it take to drain the water from the base layer given the design parameters specified (i.e. length of time for the regeneration of storage capacity)?

PCSWMMPP uses the USEPA SWMM4.30 program as its underlying engine. While the SWMM engine was not explicitly developed for modeling permeable pavements, we believe it is generic and powerful enough to be adapted to this use. Only a small portion of the capabilities of SWMM is used in PCSWMMPP, specifically, the surface routing, infiltration, and groundwater routines. For our purposes the Runoff module represents the permeable pavement installation as an idealized catchment with certain surface infiltration properties, and subsurface properties. The Runoff module accepts an arbitrary rainfall hyetograph and makes a step by step accounting (conservation of mass) of water movement through the permeable pavement installation: surface detention, overland flow, infiltration, subsurface storage, and subsurface drainage.

In the following sections, the modeling theory and the adaptation of SWMM for permeable pavement modeling is examined. For more detailed explanations of methods and techniques, readers should refer to the SWMM documentation (Huber and Dickinson, 1988; James et al, 1998).

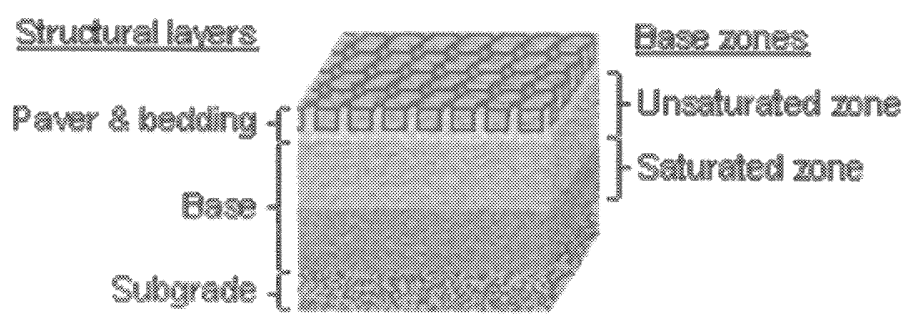

Figure 26.3 Permeable paver model components. 
As illustrated in Figure 26.3, the permeable pavement model comprises four distinct components:

1. the paver and bedding layer,

2. the unsaturated zone of the base material,

3. the saturated zone of the base material, and

4. the subgrade.

These components are assumed to be homogenous, at least as far as the modeled hydrological processes are concerned. The movement of water through the porous pavement installation is controlled by five processes as shown in Figure 26.4. Each of these processes is accounted for in the model, and details of each are given below.

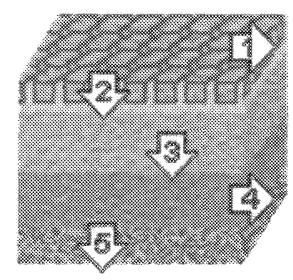

1. Surkace runotf (if amy)

2. Infitration through paver bedding

3. Percoletion through unsatur ated zone of base

4. Lateral drainage of base water

5. Deep percolation through subgrade

Figure 26.4 Processes modeled.

The model's input function (driving force) takes the form of a userspecified rainfall hyetograph (a design storm). The output functions of the model include a time history of the surface runoff flow rate, water depth in base, and lateral drainage flow rate, for the duration of the model simulation period. From these output functions, some objective functions are calculated, including the maximum depth of water in the base, the total volumes of water escaping in surface runoff (if any), lateral base drainage, and deep percolation, and the remaining water in the base.

The success of the design is determined from the output functions of the model. For a design to be deemed successful, the permeable pavement installation must capture all the stormwater falling on the surface of the installation. In other words, there must be no surface ponding or surface runoff for the duration of the simulation.

As indicated earlier, the PCSWMMPP interface limits the SWMM program to simple permeable pavement designs. A number of the parameters required by the model are not available for input by the user - they have been assigned default values based on assumptions of paver properties. 


\subsubsection{Surface Runoff}

There are three possible fates of rainfall falling on the surface of a permeable pavement installation:

1. infiltration to the base material,

2. evaporation, or

3. runoff (overland flow).

The model's conversion of rainfall excess (rainfall less infiltration and/or evaporation) into runoff is discussed in this section. Runoff (if any) is generated from the surface of the porous pavement installation by approximating it as a non-linear reservoir. The non-linear reservoir is established by coupling the Manning's equation in US units with the continuity equation:

$$
Q=W \frac{1.49}{n}\left(d-d_{p}\right)^{5 / 3} S^{1 / 2}
$$

where:

$$
\begin{aligned}
Q & =\text { runoff } \\
W & =\text { width of catchment } \\
n & =\text { Manning's roughness coefficient } \\
d & =\text { depth of surface water } \\
d_{p} & =\text { depth of depression storage } \\
S & =\text { slope of catchment }
\end{aligned}
$$

and,

$$
\frac{d V}{d t}=A \cdot i^{*}-Q
$$

where:

$$
\begin{aligned}
A & =\text { area } \\
i^{*} & =\text { rain excess } \\
& =\text { rain intensity - evaporation rate }- \text { infiltration rate }
\end{aligned}
$$

This is a spatially "lumped" configuration and assumes no special shape. However, if the catchment width $W$ (an input parameter in the SWMM Runoff module) is taken to represent the width of overland flow, then the non-linear reservoir will behave as a rectangular drainage area.

Of the variables presented in the equations above, only area, slope and width are user-definable through the PCSWMMPP interface. The remaining two parameters, roughness and depth of depression storage, are set by the program as they are defined by the properties of the permeable pavement surfaces. Each of these parameters is discussed below. 


\section{Maximum length of overland flow $L$}

Normally, the catchment width $(W)$ parameter is used as a calibration parameter (i.e. adjusted to calibrate the SWMM model to observed runoff hydrographs). However, at least in the case of rectangular catchments, the maximum length of overland flow $(L)$, when used in combination with the area of the catchment $(A)$, provides a good estimate of the catchment width parameter since $W=A / L$. This parameter $(L)$ represents the length of the longest overland flow pathway to the inlet (surface drainage) location. The maximum length of overland flow appears as a parameter in the Input Wizard.

As this model limits the user to single catchment installations (normally SWMM allows the catchment area to be divided into any number of subcatchments - each one being modeled as discussed above), the maximum length of overland flow parameter may be modified to account for extra storage in the system. If a drainage network exists, more storage will be present in the design than can be modeled here. This storage attenuates and somewhat delays the runoff hydrograph peaks and allows for greater infiltration. The lost storage can be accounted for by increasing the maximum length of overland flow (and thus reducing the "width" of the catchment). The amount of this adjustment is left to the discretion of the user.

\section{Installation area $A$}

The surface area of the installation is assumed to be the extent of the catchment area - no "run-on" from adjacent surfaces is allowed. If the effects of "run-on" are important, it may be possible to approximate this additional volume through a modified design storm. This surface area also defines the area of base available for subsurface storage.

\section{Slope $S$}

The catchment slope should reflect the average along the pathway of overland flow to inlet (surface drainage) locations. For a simple geometry the calculation is the elevation difference divided by the length of flow. For more complex geometries, several overland flow pathways may be delineated, their slopes determined, and a weighted slope computed using a path-length-weighted average. Alternatively it may be sufficient to simulate what is considered to be the hydrologically dominant slope for the conditions being simulated.

\section{Manning's roughness $n$}

Surface roughness is preset by the program to a typical UNI Eco-Stone permeable pavement value of 0.03 . This value should be modified by experience, as observations become available. 
Depression storage $d_{p}$

Depression (retention) storage is a volume that must be filled prior to the occurrence of surface runoff. It represents a loss or "initial abstraction" caused by surface ponding, surface wetting, interception and evaporation. Water stored as depression storage is subject to infiltration (and evaporation), so that it is continuously and rapidly replenished. The default depression storage set by PCSWMMPP is 0.06 in $(1.5 \mathrm{~mm}$ ) (another value that will change with experience).

\subsubsection{Infiltration through pavers and bedding}

Infiltration through the paver and bedding layer is modeled using the GreenAmpt equation. It has physically-based parameters that, in principle, can be predicted a priori. The formulation is a two-stage model. The first step computes the volume of water, $F_{s}$ which will infiltrate before the surface becomes saturated. From this point onward, infiltration capacity, $f_{p}$, is computed directly by the Green-Ampt equation. Thus:

$$
\text { For } F<F_{s}: f=i \text { and } F_{s}=\frac{S_{u} \cdot I M D}{i / K_{s}-1} \text { for } i>K_{s}
$$

No calculation of $F_{s}$ for $i \leq K_{s}$.

$$
\text { For } F \geq F_{s}: f=f_{p} \text { and } f_{p}=K_{s}\left(1+\frac{S_{u} \cdot I M D}{F}\right)
$$

where:

$$
\begin{aligned}
f= & \text { infiltration rate, } \mathrm{ft} / \mathrm{sec}[\mathrm{m} / \mathrm{s}], \\
f_{p}= & \text { infiltration capacity, } \mathrm{ft} / \mathrm{sec}[\mathrm{m} / \mathrm{s}], \\
i & =\text { rainfall intensity, } \mathrm{ft} / \mathrm{sec}[\mathrm{m} / \mathrm{s}], \\
F & =\text { cumulative infiltration volume for this event, } \mathrm{ft}[\mathrm{m}], \\
F_{s}= & \text { cumulative infiltration volume required to cause sur- } \\
& \text { face saturation, } \mathrm{ft}[\mathrm{m}], \\
S_{u}= & \text { average capillary suction at the wetting front, } \mathrm{ft} \text { water } \\
I M D & {[\mathrm{~m}], } \\
K_{s}= & \text { initial moisture deficit for this event, } \mathrm{ft} / \mathrm{ft}[\mathrm{m} / \mathrm{m}], \text { and } \\
& \text { saturated hydraulic conductivity of soil, } \mathrm{ft} / \mathrm{sec}[\mathrm{m} / \mathrm{s}] .
\end{aligned}
$$

Infiltration is thus related to the volume of water infiltrated as well as to the moisture conditions in the paver and bedding layer. For time steps where the water level in the installation has risen to the surface, the amount of infiltration is set to zero. The Green-Ampt infiltration equation has three parameters to be specified $S_{u}, K_{s}$ and $I M D$. 


\section{Saturated hydraulic conductivity $K s$}

The saturated hydraulic conductivity $K_{s}$ is also referred to as the permeability of the material. This parameter is entered in units of either in $/ \mathrm{h}$ or $\mathrm{mm} / \mathrm{h}$ and defines the rate at which water moves through the paver/bedding layer when saturated.

\section{Moisture Deficit IMD}

The moisture deficit IMD is defined as the fraction difference between soil porosity and actual moisture content. Coarse bedding materials tend to have lower porosities than fine bedding materials, but drain to lower moisture contents between storms because the water is not held to the same extent in the pores. Consequently, IMD for dry antecedent conditions tends to be higher for coarse bedding materials. This parameter is the most sensitive of the three parameters.

\section{Capillary suction $S_{u}$}

The average capillary suction $S_{u}$ is perhaps the most difficult parameter to measure. It can be derived from soil moisture-conductivity data but such data are rare for most soils. It is very difficult to give satisfactory estimates of infiltration parameters that will apply to all soils encountered - the user should be prepared to adjust preliminary estimates in the light of available data such as infiltrometer tests, measurements of runoff volume, or local experience.

\subsubsection{Percolation through the unsaturated zone of the base}

Percolation represents the vertical flow of water from the unsaturated zone of the base layer to the saturated zone of the base layer, and is the only inflow for the saturated zone. This process is modeled with the groundwater subroutine (GROUND). GROUND simulates two zones - an upper (unsaturated) zone and a lower (saturated) zone (James and Ulan, 1997, provide a recent review of the algorithm). For the purposes of this application, both zones are contained in the homogeneous base layer of the permeable pavement installation.

The flow from the unsaturated to the saturated zone is controlled by a percolation equation for which parameters may either be estimated or calibrated, depending on the availability of the necessary base data. The water available for base percolation is calculated at each time step as the volume of water infiltrating to the base from the surface of the installation (i.e. infiltrating through the paver and bedding layer). The groundwater subroutine can include losses from the upper zone (evapotranspiration) and losses and outflow from the lower zone (deep percolation, saturated zone evapotranspiration, and base 
lateral drainage. As only single event simulations (short duration) are possible, evapotranspiration is assumed to be negligible and is thus zeroed out. Deep percolation to the subgrade and lateral base drainage are discussed in the following sections. Again, readers should refer to the SWMM documentation for a more rigorous discussion of the SWMM groundwater routines.

The percolation equation used was formulated from Darcy's Law for unsaturated flow, in which the hydraulic conductivity $K$ is a function of the moisture content $T H$. The final form is:

$$
P E R C=H K T H \cdot\left[1+P C O \cdot \frac{(T H-F C)}{D W T 1 / 2}\right]
$$

and

where:

$$
H K T H=H K S A T \cdot E X P[(T H-F C) \cdot H C O]
$$

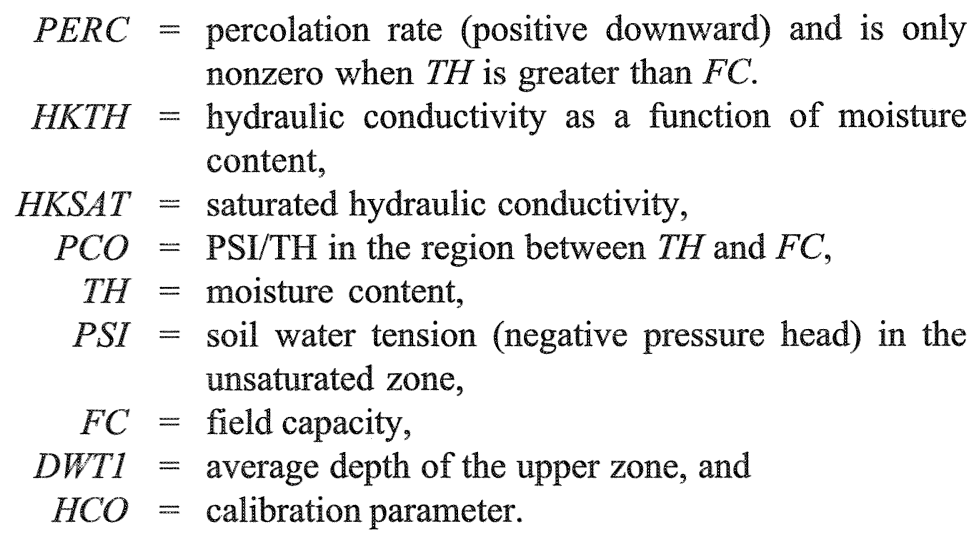

HKSAT, PCO, TH, FC and $H C O$ are all parameters required by the percolation component of the model.

This equation was developed to address the vertical movement of water through natural soils. In this application, it is used to model movement through the large pores of a uniform base material (e.g. crushed stone). There is very little information available on the suitability of this equation for modeling this type of percolation. A further concern is the lack of data on suitable parameter values. However, it is unlikely that percolation through the base material will be a controlling factor in permeable pavement design. In other words, the initial infiltration of water through the paver/bedding layer is a comparably slow process - once the water reaches the unsaturated zone of the base, it should move quite quickly to the saturated zone. 


\subsubsection{Lateral drainage of the saturated zone of the base}

Base layer discharge represents lateral flow from the saturated zone of the base to the receiving water (e.g. drainage tile outlet). The flow equation adopted for this application is:

$$
G W F L W=A l \cdot(D 1-B C)^{B l}
$$

where:

$$
\begin{aligned}
\text { GWFLW }= & \text { beginning-of-time-step base layer discharge flow rate } \\
& \text { (per installation area) } \\
A 1= & \text { lateral drainage coefficient } \\
B 1= & \text { lateral drainage exponent, } \\
D 1= & \text { depth of saturated zone, and } \\
B C= & \text { elevation of bottom of drainage system. }
\end{aligned}
$$

The user-specified parameters in this equation are $A 1, B 1$, and $B C$. The elevation of the bottom of the drainage system $B C$ indicates the base layer water elevation below which there is no lateral drainage - if the depth of the saturated zone $D 1$ is less than $B C, G W F L W$ is set equal to zero. In drainage tile systems this normally corresponds to the invert elevation of the drainage tile. The functional form of the equation was selected in order to approximate various horizontal flow conditions. Since base layer drainage flow can be a significant volume, an average flow for each time step is found by iteration. The effect of receiving water elevation on drainage flow is assumed to be negligible for this system and no reverse flow is permitted (i.e. filling of the base layer from reverse flow in the drainage system).

\subsubsection{Deep percolation through the subgrade}

Deep percolation represents a lumped sink term for unquantified losses from the saturated zone of the base. The two primary losses are assumed to be percolation through the confining layer and lateral outflow to somewhere other than the receiving water. The arbitrarily chosen equation for deep percolation is:

$$
D E P P R C=D P \cdot \frac{D 1}{D T O T}
$$

where:

$$
\begin{aligned}
D E P P R C= & \text { beginning-of-time-step deep percolation rate } \\
D P= & \text { percolation coefficient }- \text { a recession coefficient de- } \\
& \text { rived from interevent water table recession curves, }
\end{aligned}
$$




\section{$D 1=$ depth of saturated zone, and \\ $D T O T=$ depth of base layer}

The ratio of $D 1$ to $D T O T$ allows $D E P P R C$ to be a function of the static pressure head above the confining layer (subgrade). Although $D E P P R C$ will be small in most cases, it is included in the iterative process so that an average over the time step can be used. By using the average, large continuity errors will be avoided should $D E P P R C$ be set at a larger value.

The percolation coefficient $D P$ is the only user-definable variable in this equation. Setting $D P$ to a typical saturated hydraulic conductivity $k$ for the subgrade soil type is a starting point. However, assigning a saturated hydraulic conductivity to $D P$ is probably an overly conservative approach as (i) following the logic of the equation above, this percolation rate would only be achieved when the entire base material is saturated, and (ii) it assumes that the subgrade is fully saturated at the start of the simulation. Normally the infiltration rate is higher for unsaturated soils. Also, the user should note that $\mathrm{k}$ values have a wide range - sometimes 1000 fold even in the same soil classification. The final selection of $D P$ is left to the user.

\subsection{Model Interface}

As discussed previously, the basic function of PCSWMMPP is to facilitate the use of SWMM in the evaluation of permeable pavement designs. The interface allows the user to develop a permeable pavement design and evaluate its performance with one or more design storms. The interface is divided into three main sections: (i) Input Wizard, (ii) Summary Report and (iii) Graph(s). A screen capture of the Input wizard portion is shown in Figure 26.5

\section{Input Wizard}

In this section, the user can: create new permeable pavement design projects; enter the required parameter values for the project; perform an analysis of the project design (i.e. run SWMM); and examine a quick summary of the analysis results (i.e. whether the design was successful or not). The Input Wizard guides the user through the process of developing a permeable pavement design in five successive steps. Each step focuses on the parameters required for one of the five processes identified. Help for each step is provided through on-screen illustrations and hyper-links. Users can revisit the Input Wizard at any time to modify any parameters and rerun the analysis. The design project can be saved and subsequently reopened at any time. 


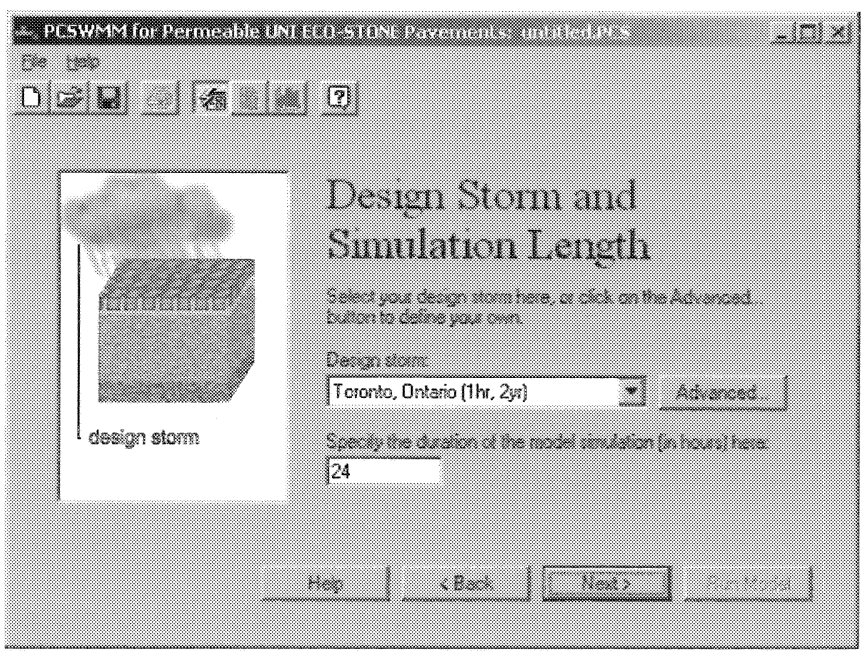

Figure 26.5 PCSWMM for Permeable Pavements: Input Wizard.

\section{Summary Report}

The Summary Report displays both the selected design parameter values and the analysis results. The report highlights a number of objective functions. These include the maximum depth of water reached in the base material, the total volumes of water escaping in surface runoff (if any), lateral base drainage, and deep percolation, and the remaining water in the base. A continuity balance is also provided for determining the scope of the computational errors (if any). This report can be copied to the clipboard for pasting into reports, or printed to the default printer. The report's analysis results are extracted from the SWMM output file generated by the SWMM engine. The original output file, which contains extensive information and additional timeseries, can be accessed from the Summary menu. The SWMM output file should be checked for error messages and reasonable run results.

\section{Graphs}

Output functions of the model are all in the time domain and can be most easily analyzed in the form of graphs. This section provides the user with graphs of the outflow time series of water from the base drainage system, the surface runoff (if any) from the installation, and the depth of water in the base material. A fourth graph displays the input function (design storm) that drives the simulation. Any combination of graphs can be chosen for display and can be customized and/or zoomed in. The displayed graph(s) can be copied to the clipboard for pasting into reports as a high-resolution metafile or printed to the default printer. 


\subsection{Parameter Estimation}

Users can select either metric or U.S. units. For all input parameters, the user is encouraged to obtain the most reasonable values from field observations (i.e. test installations or similar). As is often the case, there is usually little or no data available for calibration, and inference from the model results must be cautious.

\subsubsection{Step 1: Permeable Pavement Details}

Parameters relating to the paver/bedding layer are specified by the user. Default bedding material is a uniform sand, $2-5 \mathrm{~mm}$.

\section{Age of Installation}

The age of the permeable pavement installation affects the permeability of the paver/bedding material layer. As time passes from the date of installation, the infiltration rate of the paver/bedding layer generally decreases. In the model, this "clogging" effect is represented by a modification of the Green-Ampt infiltration equation's parameters (average capillary suction, saturated hydraulic conductivity, and initial moisture deficit). The user has the option of selecting an age of installation from the drop-down list or specifying the paver layer infiltration parameters directly by clicking on the "Advanced" button. The four age groups are:

1. new installation

2. $1-3 \mathrm{y}$

3. $4-5 \mathrm{y}$

4. older than $6 \mathrm{y}$

It is important to remember that parameter values applicable for the bedding material must be adjusted to take into account the impervious components of the paver/bedding layer (i.e. the pavers themselves). SWMM assumes a spatially uniform infiltration throughout this layer, whereas in reality the infiltration is limited to the bedding filled openings between the pavers approximately $12 \%$ of the total installation area. The Green and Ampt parameters should be chosen to represent a theoretical uniform material with the equivalent infiltration properties of the installation's mixed material paver/ bedding layer, as given in Table 26.1 .

Average capillary suction of the bedding/drainage cell material is entered in $\mathrm{mm}$ or inches. However, if the soil suction vs. moisture content curve is available, a better value to use would be the soil suction for the initial moisture content. The default average capillary suction is $10 \mathrm{~mm}$ for all ages of bedding. The rate at which water moves through the paver/bedding layer is given by the saturated hydraulic conductivity, expressed in $\mathrm{mm} / \mathrm{h}$ or in $/ \mathrm{h}$. Table 26.1 shows 
the assumed values for various ages of uniform sand bedding material (SoenkeBorgwardt, 1994, 1997; Cao 1998):

Table 26.1 Saturated hydraulic conductivity at various ages.

\begin{tabular}{lll}
\hline Age of Installation & $\mathrm{K}_{\mathrm{s}}(\mathrm{in} / \mathrm{hr}, \mathrm{mm} / \mathrm{h})$ & Equivalent $\mathrm{K}_{\mathrm{s}}$ \\
\hline New installation & $140 \mathrm{in} / \mathrm{h}, 3600 \mathrm{~mm} / \mathrm{h}$ & $17 \mathrm{in} / \mathrm{h}, 430 \mathrm{~mm} / \mathrm{h}$ \\
1 - 3 y & $80 \mathrm{in} / \mathrm{h}, 2100 \mathrm{~mm} / \mathrm{h}$ & $10 \mathrm{in} / \mathrm{h}, 250 \mathrm{~mm} / \mathrm{h}$ \\
$4-5 \mathrm{y}$ & $70 \mathrm{in} / \mathrm{h}, 1800 \mathrm{~mm} / \mathrm{h}$ & $8 \mathrm{in} / \mathrm{h}, 200 \mathrm{~mm} / \mathrm{h}$ \\
Older than $6 \mathrm{y}$ & $14 \mathrm{in} / \mathrm{h}, 360 \mathrm{~mm} / \mathrm{h}$ & $2 \mathrm{in} / \mathrm{h}, 40 \mathrm{~mm} / \mathrm{h}$ \\
\hline
\end{tabular}

The initial moisture deficit is equal to the initial moisture content subtracted from the soil porosity, expressed as a percentage. For conservative design, initial moisture content should be set to field capacity. Since the bedding material is composed of sand, the initial moisture deficit is relatively high as compared to natural soil. An initial moisture deficit of $50 \%$ has been selected as the default value for all ages of installation.

The pre-selected average capillary suction and initial moisture deficit values are deemed to be conservative estimates by the authors, but are not based on any published values. The user is encouraged to determine local values for these parameters.

\section{Permeable Pavement Area}

This is the total area of the permeable pavement installation, entered in acres/ hectares. This area must be completely covered with the pavers - no adjoining pervious or impervious surfaces should be included. The model does not allow for run-on from adjoining surfaces - the sole source of water for the simulation is the rainfall directly hitting the permeable pavement installation.

\subsubsection{Step 2: Base Details}

Parameters selected are used to determine the storage capacity of the base material and the percolation rate of water through the unsaturated zone of the base material (i.e. the vertical flow of the infiltrated water from the paver/bedding layer to the surface of the water table in the base material).

\section{Type of base material}

The type of base material can be chosen from a drop-down list. The types provided in the program set default values for the hydraulic properties of the base material including; porosity, saturated hydraulic conductivity, field capacity and the relationships of soil-water tension and hydraulic conductivity to 
moisture content. The user has the option of specifying these base parameters directly in an "Advanced" screen. The pre-selected base materials include an open graded base ASTM No 57 and a cement-stabilized base utilizing No 57. For more information on base materials and their properties, please contact your local rock and pavement aggregate supplier. The default values for porosity and saturated hydraulic conductivity for open graded base material were obtained from Ferguson (1994), and cement stabilized base material were obtained from ACPA (undated).

Table 26.2 Characteristics of base material.

\begin{tabular}{|c|c|c|c|c|c|}
\hline Base Material & $\begin{array}{l}\text { Porosity } \\
\text { (fraction) }\end{array}$ & $\begin{array}{l}\text { Saturated } \\
\text { hydraulic } \\
\text { conductivity }\end{array}$ & $\begin{array}{l}\text { Field } \\
\text { capacity }\end{array}$ & $\begin{array}{l}\text { Curve } \\
\text { fitting } \\
\text { parameter }\end{array}$ & $\begin{array}{l}\text { Tension- } \\
\text { soil moisture }\end{array}$ \\
\hline $\begin{array}{l}\text { Open graded } \\
\text { Base ASTM } \\
\text { No } 57\end{array}$ & 0.38 & $\begin{array}{l}3500 \mathrm{in} / \mathrm{h}, \text { or } \\
90000 \mathrm{~mm} / \mathrm{h}\end{array}$ & 0.05 & 10 & $\begin{array}{l}15 \mathrm{ft} / \text { fraction, } \\
\text { or } \\
5 \mathrm{~m} / \text { fraction }\end{array}$ \\
\hline $\begin{array}{l}\text { Cement } \\
\text { stabilized } \\
\text { Base, utilizing } \\
\text { No. } 57\end{array}$ & 0.33 & $\begin{array}{l}4000 \mathrm{in} / \mathrm{h} \text { or } \\
110000 \mathrm{~mm} / \mathrm{h}\end{array}$ & 0.05 & 10 & $\begin{array}{l}15 \mathrm{ft} / \text { fraction, } \\
\text { or } \\
5 \mathrm{~m} / \text { fraction }\end{array}$ \\
\hline
\end{tabular}

Porosity is the relationship between the volume of voids and the total volume of the base material (expressed as a fraction). Porosity defines the total amount of water that the base course can store. Porosity is synonymous with soil moisture content at saturation since under this condition all available pore space is filled with water.

The saturated hydraulic conductivity $K_{s}$ of a material can range over many orders of magnitude. Many empirical equations exist that relate hydraulic conductivity to the percentage of fine particles. However, these equations often incorporate an empirical constant which many users may not be able to estimate. Thus, an approximation based on published data may be the best method to determine the saturated hydraulic conductivity if direct measurement is not possible.

Field capacity is achieved when a saturated soil has been fully drained by gravity. This moisture condition is often assumed to occur at a soil suction of $1 / 3 \mathrm{~atm}$. The most common method in determining field capacity is by plotting moisture content vs. soil suction from experimental data. This parameter is entered as a fraction of moisture volume to saturated moisture volume. The estimated field capacity is probably conservative (real values may be lower).

The curve fitting parameter is a dimensionless number that is used to describe the hydraulic conductivity vs. moisture content curve. The calculated curve should have good correspondence with the experimental curve for high 
moisture content values. In particular, the range between saturation and field capacity (i.e. the region of fluctuation during a storm simulation) should closely resemble the fitting parameter. The default values provided by the program are not from any published source and should be replaced by the user with local values.

The tension-soil moisture parameter is the average slope of the soil suction vs. moisture content curve and is given in $\mathrm{m} /$ fraction or $\mathrm{ft} /$ fraction. Again, the region that should be described is the range lying between saturation and field capacity. The default values provided in PCSWMMPP are not from any published source and should be replaced by the user with local values.

\section{Depth of base material}

The depth of base material is specified in meters or feet and corresponds to the change in elevation between the top of the subgrade and the bottom of the paver/ bedding layer.

\section{Initial depth of water in base material}

Antecedent conditions and the base drainage capability of the installation should be considered for determining the initial depth of water in the base layer. Normally this parameter would be set to zero, however in cases where the subgrade is fairly impermeable (e.g. clay) and there is little or no lateral drainage, a value greater than zero would be desirable. Of course, the greater this value the less storage volume is available in the base material for the infiltrating stormwater.

\section{Initial moisture content of unsaturated zone}

As with all input parameters, the initial upper zone moisture content should be measured by the modeler. However, in practice this is usually impractical or impossible. When assigning this value, the antecedent conditions must be considered. The initial moisture content has a practical range between field capacity and wilting point. Values are unlikely to be greater than field capacity due to the high drainage capabilities of the base material. Moisture losses through the surface of the pavement should be low. The only mechanisms whereby moisture content can be reduced from field capacity are evaporation and evapotranspiration by plants. Since water movement cannot occur through the concrete pavers, the relative surface area of the drainage cells are small, and plants are generally absent, a good estimate of initial moisture content is field capacity. 


\subsubsection{Step 3: Drainage and Subgrade Details}

This step prompts the user to define parameters that control water outflow from the system, either through vertical movement into the subgrade (deep percolation) or lateral movement out of the base via either bulk flow through the base material or flow through drainage tile(s).

\section{Type of lateral base drainage}

Selecting the type of lateral base drainage sets default values for the variables of the equation that defines the horizontal outflow of water from the saturated zone of the base. Three types of drainage are available:

1. no drainage,

2. slow drainage, and

3. fast drainage.

As before, these drainage parameters (threshold elevation, flow exponent and coefficient) can be explicitly specified in an "Advanced" screen.

Threshold elevation is the height of the saturated zone of the base below which there is no base drainage. For all the listed types of drainage, the threshold elevation has been set to the elevation of the bottom of the base.

The flow coefficient and flow exponent parameters describe the lateral movement of water out of the base layer. The drainage types listed have arbitrarily assigned coefficients and exponents. Choosing an exponent other than zero will make the drainage dependant on the depth of water above the threshold elevation. These parameters should be updated to reflect design specific drainage flow rates.

Table 26.3 Types of lateral base drainage.

\begin{tabular}{lll}
\hline Type of drainage & Flow coefficient & Flow exponent \\
\hline No drainage & $0 \mathrm{in} / \mathrm{hr}-\mathrm{ft}, 0 \mathrm{~mm} / \mathrm{h}-\mathrm{m}$ & 0 \\
Slow drainage & $1 \mathrm{in} / \mathrm{hr}-\mathrm{ft}, 83 \mathrm{~mm} / \mathrm{h}-\mathrm{m}$ & 2 \\
Fast drainage & $1000 \mathrm{in} / \mathrm{hr}-\mathrm{ft}, 83000 \mathrm{~mm} / \mathrm{h}-\mathrm{m}$ & 2 \\
\hline
\end{tabular}

\section{Subgrade soil type}

Selecting the subgrade soil type assigns a value for the percolation coefficient. This parameter (entered in $\mathrm{mm} / \mathrm{h}$ or in $/ \mathrm{h}$ ) allows the user to control the percolation rate of the subgrade, thus controlling the rate at which water is lost from the base layer. Selecting a subgrade soil type will set $D P$ to a typical saturated hydraulic conductivity $k$ for that soil type, as per the following table (Rollings and Rollings, 1993): 
Table 26.4 Subgrade soil types.

\begin{tabular}{lll}
\hline Soil Type (SCS symbols) & \multicolumn{2}{c}{ Sat. Hydraulic Conductivity $k$} \\
\hline & $\mathrm{mm} / \mathrm{h}$ & in $/ \mathrm{h}$ \\
\hline Sand \& Gravel Mix (GW,GP,SW,SP) & 23 & 0.9 \\
Silty Gravels to Silts (GM,SM,ML,MH,OL) & 10 & 0.4 \\
Silty Clay to Sandy Clay (SC,CL) & 5 & 0.2 \\
Clays (CH,OH) & 2.5 & 0.1 \\
Impervious & 0 & 0 \\
\hline
\end{tabular}

Note that $k$ has a wide range - even in the same soil classification. Also, assigning a saturated hydraulic conductivity to $D P$ is probably a conservative approach as, (i) following the logic of the equation above, this percolation rate would only be achieved when the entire base material is saturated, and (ii) it assumes the subgrade is fully saturated at the start of the simulation. Normally the infiltration rate is higher for unsaturated soils. The final selection of percolation coefficient is left to the user.

\subsubsection{Step 4: Specifying a design storm and the simulation duration}

In the final step the input function (design storm) and the duration of simulation is specified. The input function takes the form of a hyetograph, which can be described by up to 12 data points (rain intensity in $\mathrm{mm} / \mathrm{h}$ or in $/ \mathrm{hr}$ ). The time step between data points can be of any length but must be constant for the entire input function time series. In this way any length of design storm can be accommodated, however the time step size increases for longer duration design storms. In most cases a 1-h design storm (described by 12 data points at a 5 minute interval) with a return period of 2 y would be ideal for the typical, spatially small, permeable pavement model. A number of design storms have been supplied for various regions, however it is recommended that the user specify their own regional design storm under an advanced screen. The depths of the supplied design storms were obtained from the Rainfall Frequency Atlas of both Canada (Hogg and Carr, 1985) and the USA (Hershfield, 1981), and include the $5,10,15,30$ and 60 minute duration rainfall depths for the $2 y$ return period in each design storm.

The duration of the model simulation is the length of time (h) over which the model will be run. The optimal duration of simulation depends on the duration of the input function and the speed at which the stormwater moves through the permeable pavement design. A longer duration is required to compute the time it takes to completely drain the base layer of stormwater. 


\subsection{Determining the Success of the Design and Model Validation}

After the steps of the Input Wizard have been completed, all that remains is to run the model and review the results. After the run, PCSWMMPP automatically loads the results (from the output file generated by SWMM), checks for a successful run and prepares the Summary Report and the Graphs.

Assuming that the SWMM engine does not report unacceptable continuity errors or other problems with the design, the success of the run is dictated by whether the depth of water in the base material remained less than $85 \%$ of the base depth throughout the run (Borgwardt, 1997). If the saturation of the base material exceeds $85 \%$, the base thickness should be increased accordingly. The Analysis Results screen of the Input Wizard (which appears after a model run) indicates whether the design was successful. This judgement is based solely on the maximum depth of water reported by SWMM in the base layer. There may be other problems with the model that invalidate the results, yet produce an otherwise reasonable maximum depth of water in the base layer. Hence users are advised not to rely solely on the Analysis Results screen for model validation.

After the model has been run, the selected parameters can be adjusted if needed (by returning to the appropriate Input Wizard step) and the model rerun. The design can be saved to a file for future analysis/editing.

\section{Model Validation}

Validation of a model such as SWMM is difficult without calibration data. Since most permeable pavement design applications have little in the way of existing data, we are left to subjectively judge the reasonableness of the model output. The first step after a model run is to check the continuity balances that are reported by SWMM. There are separate continuity balances calculated for the surface processes, the subsurface processes and the channel/pipe processes, and are available in the generated Summary Report. It is left to the user to determine the maximum acceptable continuity error for the model results. However, if the continuity balance for any one of these three checks exceeds $6 \%$ a warning is given at the end of the model run.

\subsection{Conclusions}

Rather than making a simplistic solution seem technically advanced, PCSWMMPP renders the powerful and complex SWMM model easy to use. The program allows quick implementation of a BMP in SWMM. Exceptionally 
user-friendly, it is freely available from any of the authors. Readers should note however that to the authors' knowledge, the SWMM code for groundwater and infiltration has not been comprehensively tested against a specific permeable pavement field program - in other words, the new permeable paver code has technically not been verified. Until the code is field proven, questions remain on the applicability of the percolation routine of the Runoff module to open graded base materials such as crushed rock.

\section{Acknowledgments and Limitations}

This work is based on the findings of a sequence of Bill's graduate students. In reverse chronology, they are: Craig Kipkie, Chris Kresin, Brian Verspagen, Reem Shahin, Mike Thompson, Julie Ulan and Jenny Xie. Special mention goes to Nick Emery, who performed a literature search for parameter estimates.

$\mathrm{UNI}^{\circledR}$ and ECO-STONE ${ }^{\circledR}$ are trademarks of F. von Langsdorff Licensing Ltd. PCSWMM is a trademark of Computational Hydraulics Int. PCSWMMPP is only a tool to aid design and for general guidance. It is intended solely for use by professional civil engineers that are competent to evaluate the significance and limitations of the computations and results. The software is not a substitute for engineering skill and judgement and in no way should replace the services of experienced and professionally qualified civil engineering consultants. Further, PCSWMMPP is an interface for SWMM - the results are produced by SWMM and no guarantee is made by Computational Hydraulics Int. or F. von Langsdorff Licensing Ltd. as to the validity of these results. Full responsibility for the use of this software for any project remains wholly with the user.

\section{References}

ACPA (undated), Cement-treated permeable base for heavy-traffic concrete pavements, American Concrete Pavement Association

Cao, Su Ling, Daryl Poduska and Dan G. Zollinger, 1998, Drainage design and performance guidelines for UNI ECO-STONE permeable pavement, UNI-GROUP U.S.A.

Ferguson, Bruce K., 1994, Stormwater infiltration. Lewis Publishers.

Hershfield, D.M., 1961, Rainfall frequency atlas of the United States, Technical paper no. 40, Engineering Division, Soil Conservation Service, U.S. Dept. Agriculture.

Hogg, W.D. and D.A. Carr, 1985, Rainfall frequency atlas for Canada, Atmospheric Environment Service. Environment Canada.

Huber, Wayne C. and Robert E. Dickinson. 1988 Storm Water Management Model, Version 4: User's Manual. Environmental Research Laboratory, United States Environmental Protection Agency, Athens, Georgia. 
James, R. and W. James. 1995. "An Error-Control Decision Support System for SWMM." Journal of Water Management Modeling R183-21. doi: 10.14796/JWMM.R183-21.

James, W., Huber, W.C., and James, W. R.C. 1998. Water systems models HYDROLOGY - student's guide to SWMM4 RUNOFF and related modules. CHI pubs R199. Guelph.

James, W. and R. Shahin. 1997. "A Laboratory Examination of Pollutants Leached from Four Different Pavements by Acid Rain." Journal of Water Management Modeling R200-17. doi: 10.14796/JWMM.R200-17.

James, W. and M.K. Thompson. 1996. "Contaminants from Four New Pervious and Impervious Pavements in a Parking-lot." Journal of Water Management Modeling R195-11. doi: 10.14796/JWMM.R195-11.

James, W. and J.A. Ulan. 1997. "Utility of shallow groundwater routines for modelling in filtration BMPs in urban stormwater models." Journal of Water Management Modeling R200-12. doi: 10.14796/JWMM.R200-12.

James, W. and B. Verspagen. 1996. "Thermal Enrichment of Stormwater by Urban Pavement." Journal of Water Management Modeling R195-08. doi: 10.14796/JWMM.R195-08.

James, W. and J. Xie. 1999. "Modeling Thermal Enrichment of Streams due to Solar Heating of Local Urban Stormwater." Journal of Water Management Modeling R204-08. doi: 10.14796/JWMM.R204-08.

Kipkie, C. and W. James. 1999. "Feasibility of a Permeable Pavement Option in SWMM for Long-term Continuous Modeling." Journal of Water Management Modeling R206-18. doi: 10.14796/JWMM.R206-18.

Kresin, C., W. James and D. Elrick. 1996. "Observations of Infiltration Through Clogged Porous Concrete Block Pavers." Journal of Water Management Modeling R195-10. doi: 10.14796/JWMM.R195-10.

Rollings, Raymond S. and Marian P. Rollings, 1993, Design considerations for the UNI ECO-STONE concrete paver, UNI-GROUP U.S.A.

Soenke Borgwardt, 1994, Test performed on UNI ECO-STONE pavements of various ages, University of Hannover, Germany.

Soenke Borgwardt, 1997, Performance and fields of application for permeable paving systems, BFT 2/97, Germany.

Thompson, M.K. and W. James. 1995. "Provision of Parking Lot Pavement for Surface Water Pollution Control Studies." Journal of Water Management Modeling R183-24. doi: 10.14796/JWMM.R183-24.

Xie, D.M. and W. James. 1994. "Modelling Solar Thermal Enrichment of Urban Stormwater." Journal of Water Management Modeling R176-13. doi: 10.14796/JWMM.R176-13. 